\title{
COMPOSIÇÃO E ESTRUTURA DO FITOBENTOS DO INFRALITORAL DA RESERVA BIOLÓGICA MARINHA DO ARVOREDO, SANTA CATARINA, BRASIL - IMPLICAÇÕES PARA A CONSERVAÇÃO
}

\author{
Paulo Antunes Horta ${ }^{1}$,José Pedrassoli Salles ${ }^{1}$, Janayna L. Bouzon', Fernando Scherner', Debora \\ Queiroz Cabral ${ }^{1}$ \& Zenilda L. Bouzon ${ }^{3}$ \\ ${ }^{1}$ Universidade Federal de Santa Catarina, Centro de Ciências Biológicas, Departamento de Botânica, Laboratório de Ficologia, CEP 88010-9710, \\ Florianópolis, SC, Brasil. \\ 2. Universidade Federal do PAraná, Departamento de Zoologia, Laboratório de Biologia e Ecologia de Ascidiacea. CEP: 81531-980. Curitiba, Paraná, \\ Brasil. \\ ${ }^{3}$ Universidade Federal de Santa Catarina, Centro de Ciências Biológicas, Departamento de Biologia Celular e Genética, Laboratório de Algas Marinhas, \\ CEP 88010-9710, Florianópolis, SC, Brasil. \\ E-mail: pahorta@ccb.ufsc.br
}

\section{RESUMO}

Organismos bênticos do infralitoral têm sido historicamente estudados por meio de material proveniente de dragagens, um método considerado ineficiente para o estudo da estrutura de comunidades. Poucos estudos de comunidades foram realizados com o uso de mergulho autônomo no Brasil. Este estudo descreve a estrutura da comunidade fitobêntica da Reserva Marinha do Arvoredo no sul do Brasil, e foi realizado com o uso de mergulho autônomo nas proximidades das três ilhas que estão na área da reserva. As áreas de amostragem foram escolhidas com base no seu nível de proteção ou exposição às ondas e às correntes. O infralitoral da Reserva Marinha do Arvoredo quando comparado aos de outras áreas estudadas na costa brasileira é altamente diverso. Foram identificadas 127 espécies, entre as quais, algumas nunca citadas anteriormente para o sul do Brasil e uma provável nova espécie para a ciência (genêro Callophyllis), que está sendo descrita. Sargassum vulgare foi a espécie dominante em todas as comunidades com $41,5 \%$ da biomassa média de todas as ilhas. A diversidade de Shannon variou de 0 a 1,73 na Ilha do Avoredo e Gales, respectivamente, e a riqueza de 6,6 sp.amostra-1 no banco de nódulos calcários a 20,8 sp.amostra ${ }^{-1}$ na Ilha Deserta. Um banco de nódulo calcário ocorre na área de proteção, aumentando a peculiaridade desta área. Algumas implicações para o manejo do banco, assim como para o manejo da reserva também são discutidas. Conclui-se que a área em estudo representa uma área de transição no que diz respeito à flora macroalgal, possuindo representantes típicos de áreas tropicais e temperadas. A heterogeneidade do substrato, o hidrodinamismo, efluentes orgânicos e pressões de herbivoria, distribuídos de forma diferenciada, são sugeridos como principais fatores responsáveis pela estruturação diferenciada do ficobentos nas ilhas. Considerando que esta é a única área protegida desta categoria no sul do Brasil, destaca-se a importância de outras áreas ao longo da costa brasileira também serem contempladas na categoria de áreas protegidas de uso restrito, de forma a garantir a proteção das algas e da comunidade associada para as gerações futuras.

Palavras-chave: Macroalgas bênticas, estrutura de comunidades, biodiversidade, área de proteção marinha, conservação.

\footnotetext{
ABSTRACT

SUBTIDAL PHYTOBENTHUS COMPOSITION AND STRUCTURE OF THE ARVOREDO MARINE BIOLOGICAL RESERVE, SANTA CATARINA, BRAZIL - IMPLICATIONS TO THE CONSERVATION. Benthic organisms of the subtidal region are usually studied from dredged samples, what is an inefficient approach for community structure studies. Only a few community studies in Brazil made use of scuba diving. The present study describes the phytobenthic community structure of the Arvoredo Marine Biological Reserve on the south part of Brazil. Sampling was done through scuba diving close to three islands that are part of the Reserve. The sampling sites were selected based on their degree of shelter or exposition to wave action and currents. A hundred and twenty seven species of organisms were identified. Some of species found were unprecedented to the south part of Brazil, and a potentially new species of the genus Callophyllis was found. Sargassum vulgare was the dominant species for all the sampled sites, composing $41.5 \%$ of the total biomass. There was a rhodolith bed present in a sheltered area. Shannon diversity index was 0 and 1.73 to Arvoredo and Gales islands, respectively, and the richness index was $6.6 \mathrm{sp} . \mathrm{sample}^{-1}$ for the Rhodolith bed
} 
and 20.8 sp.sample ${ }^{-1}$ for Deserta Island. We think the studied region is a transition area of seaweed flora, for presenting organisms that are typical of both tropical and temperate regions. We suggest the main factors structuring the phytobenthic communities near the islands to be substrate heterogeneity, hydrodynamics, organic effluents and grazing pressure. Minding that this is the only protected area of the category in the south part of Brazil, we stress the importance of protecting other areas of the Brazilian coast, to ensure the protection of seaweed diversity and associated organisms to future generations.

Keywords: Benthic Macroalgae, community structure, biodiversity, marine protected area, conservation.

\section{INTRODUÇÃO}

Com o avanço da urbanização, o crescimento da pesca predatória e a intensificação da explotação de organismos marinhos os diferentes ecossistemas e as comunidades de ambientes costeiros sofrem impactos crônicos e agudos (Pagliosa \& Barbosa 2006, Pagliosa et al. 2006) causando a destruição de habitat e, como conseqüência, a exclusão ou em certos casos a extinção de espécies (Phillips 1998). É neste cenário que cresce a necessidade de delimitação e criação de áreas de uso restrito ou de Unidades de Conservação.

Entretanto, quando se fala da diversidade de organismos marinhos pouco se conhece sobre o que está sendo preservado no infralitoral do sul e sudeste do Brasil. Esta região, permanentemente submersa, tem sido estudada historicamente com base em material proveniente de dragagens sendo poucos os estudos que fizeram uso de mergulho autônomo, método reconhecidamente eficiente quando aplicado a fundos rochosos ou em trabalhos que se propõem a investigar a estrutura das comunidades (Norton \& Milburn 1972, Horta \& Oliveira 2001).

Dentre os trabalhos que enfocaram o fitobentos, destacam-se os de Maggs et al. (1979), Mitchell et al. (1982), Eston et al. (1986), Eston (1987), Quége (1988), Yoneshigue \& Villaça (1989), Creed (1997), Figueiredo (1997), Creed \& Amado Filho (1999), Amado Filho et al. (2003) e Oigman-Pszczol et al. (2004), que abordaram questões variadas na região sudeste, mais freqüentemente utilizando material proveniente do litoral do Rio de Janeiro. No Brasil, mesmo as comunidades de costões rochosos que são quase exclusivas das regiões sudeste e sul (Oliveira et al. 1999), estudos relativos a comunidades de macroalgas do infralitoral vinham sendo negligenciados (Horta et al. 2001). Até os trabalhos de Horta (2000), as macroalgas do infralitoral da costa sul Brasileira ainda não haviam sido estudadas.
Em estudo recente da diversidade algal do infralitoral do Parque estadual da Laje de Santos, Amado Filho et al. (2006) revelaram uma flora algal extremamente rica e concentrada em uma área reduzida. A referida descoberta coloca em evidência as Unidades de Conservação como importantes alternativas para a preservação incluindo a diversidade de macroalgas bênticas, produtores primários indispensáveis para a estabilidade das cadeias tróficas costeiras (Chapin III et al. 1997).

No litoral do Estado de Santa Catarina destaca-se a presença da Reserva Biológica (Rebio) Marinha do Arvoredo, que forma um polígono de 17.600ha e reúne três ilhas (Figura 1), apresentando um infralitoral composto de uma ampla faixa de substrato consolidado. O presente trabalho apresenta pela primeira vez uma descrição da composição e estrutura da comunidade fitobêntica do infralitoral das ilhas que compõem a Rebio do Arvoredo, fornecendo subsídios importantes para o manejo e conseqüente preservação do respectivo ambiente.

\section{MATERIAL E MÉTODOS}

\section{ÁREA DE ESTUDO}

A Reserva Biológica Marinha do Arvoredo, criada em 1990, é a única Reserva Biológica marinha dos litorais sul e sudeste brasileiros. Está situada $11 \mathrm{~km}$ ao norte da Ilha de Santa Catarina, sendo delimitada pelas latitudes $27^{\circ} 09^{\prime} 30^{\prime \prime} \mathrm{N}$ e $27^{\circ} 17^{\prime} 57,57^{\prime \prime}$ 'S (www.ibama.gov.br). A referida reserva destaca-se por suas águas claras e pela presença de substrato consolidado em profundidades superiores a $30 \mathrm{~m}$, importantes atrativos para o crescente turismo subaquático. O polígono da reserva encontra-se dentro de uma província oceanográfica que se caracteriza pela presença da Água Central do Atlântico Sul (ACAS) durante o verão, com baixas temperaturas e elevados teores de nutri- 


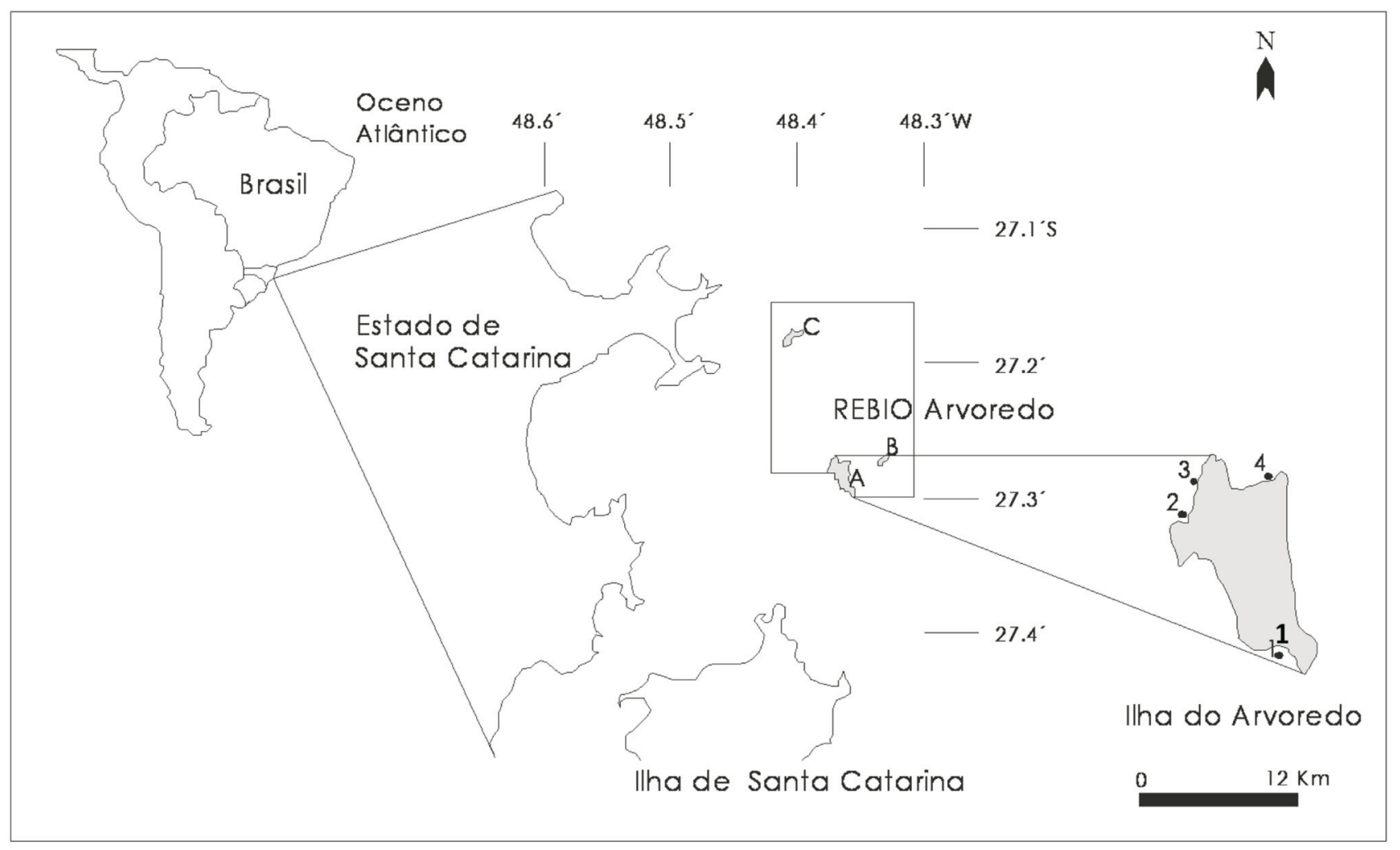

Figura 1. Mapa da área de estudo, com a Localização do polígono da Reserva Biológica Marinha do Arvoredo, destacando-se as Ilhas do Arvoredo (A), Deserta (B) e Galés (C). No detalhe da Ilha do Arvoredo - 1 = Saco do Farol; 2 = Banco de Algas Calcários; $3=$ Rancho Norte; $4=$ Saco d'água. Figure 1. Geographical location of the study area. The littoral of Santa Catarina State is zoomed, and the three islands are indicated in the box: Arvoredo (A), Deserta (B) and Galés (C). Arvoredo island is further magnified to the right, and the local studied locations are indicated: $1=$ Saco do Farol, 2 = Banco de Algas Calcários, 3 = Rancho Norte, and $4=$ Saco d'Agua.

entes; e, durante o inverno, das águas costeiras influenciadas pela corrente das Malvinas (Castro \& Miranda 1998).

Nesta área encontram-se as Ilhas da Galés, do Arvoredo e Deserta, onde foram estabelecidas 9 (nove) estações amostrais buscando representar diferentes condições ambientais, proporcionadas por diferentes graus de exposição às ondas e correntes marinhas (Figura 1). Na Ilha Deserta foram realizados mergulhos na Ponta Norte (27015'59' 'S/48 $19^{\prime} 44^{\prime}$ ' W), e na Porção Central (27 $\left.16^{\prime} 13^{\prime}, \mathrm{S} / 48^{\circ} 19^{\prime} 56^{\prime}, \mathrm{W}\right)$. Na Ilha do Arvoredo foram caracterizadas áreas do Saco do Farol (27 $17^{\prime} 48^{\prime}$ 'S $/ 48^{\circ} 21^{\prime} 30^{\prime}$ ' $\left.\mathrm{W}\right)$, dos Costões do Rancho Norte $\left(27^{\circ} 16^{\prime} 36^{\prime}\right.$ 'S $/ 48^{\circ} 22^{\prime} 27^{\prime}$ 'W), do Saco D'água $\left(27^{\circ} 16^{\prime} 23^{\prime \prime} \mathrm{S} / 48^{\circ} 21^{\prime} 47^{\prime \prime} \mathrm{W}\right)$ e do Banco de nódulos calcários $\left(27^{\circ} 16^{\prime} 22^{\prime}\right.$ 'S $/ 48^{\circ} 22^{\prime} 35^{\prime}$ 'W), este último situado sobre substrato inconsolidado. $\mathrm{Na}$ Ilha das Galés foram amostradas as estações Toca da Salema (27011'00''S/48 24'37', W), Ponta Norte $\left(27^{\circ} 10^{\prime} 32^{\prime}\right.$ 'S $/ 48^{\circ} 24^{\prime} 20^{\prime}$ ' W) e Saco da Mulata $\left(27^{\circ} 10^{\prime} 48^{\prime}, \mathrm{S} / 48^{\circ} 24^{\prime} 12^{\prime}\right.$ ' $\left.\mathrm{W}\right)$, sendo os dois primeiros pontos amostrados em substratos consolidado (10m) e inconsolidado (12m).

\section{COLETA E IDENTIFICAÇÃO DO MATERIAL}

Em janeiro de 2003 foi realizado, através de mergulho autônomo, um levantamento qualitativo prévio em cada estação. Foi feita uma amostragem sistemática para reconhecimento taxonômico, caracterização e delimitação da macro-área a ser amostrada quantitativamente.

Para a caracterização quantitativa das comunidades fitobênticas foram definidas (no período de fevereiro a março de 2003) áreas homogêneas e representativas de substrato consolidado com declividade inferior a $40^{\circ}$ e situadas entre 7 a $10 \mathrm{~m}$ de profundidade. Em áreas onde o substrato esteve presente além dos $15 \mathrm{~m}$ de profundidade (Saco do Farol e Banco de nódulos calcários da Ilha do Arvoredo) foi feita a caracterização estratificada do fitobentos amostrando-se em três faixas de profundidade de aproximadamente 5, 10 e $15 \mathrm{~m}$. Em cada área foram posicionadas trenas com 
$10 \mathrm{~m}$ de comprimento, paralelas à linha de costa, onde foram sorteados, com o uso de uma tabela de números aleatórios, quatro a sete quadrados de $25 \times 25 \mathrm{~cm}$. O número de elementos amostrais em cada uma das estações de coleta foi em função do tempo permanência de fundo disponível e da maior ou menor heterogeneidade do substrato. Áreas mais homogêneas receberam um menor número de elementos amostrais, enquanto que áreas mais heterogêneas um maior número. $\mathrm{O}$ epibentos presente no interior dos elementos amostrais foi completamente raspado (excluindo-se somente algas calcárias incrustantes) e armazenado em sacos plásticos previamente etiquetados. Ainda em campo as amostras foram fixadas em formol a $4 \%$ em água do mar. Em laboratório as amostras foram triadas e a identificação foi feita a nível de espécie. Para a obtenção do peso seco, a biomassa de cada espécie foi mantida em estufa a $50^{\circ} \mathrm{C}$ até o estabelecimento de peso constante. Na Ilha da Galés, na Ponta Norte e Toca da Salema, o fitobentos observado sobre o substrato não consolidado das áreas adjacentes aos costões também foi amostrado. A metodologia utilizada para estes ambientes foi a mesma descrita para o substrato consolidado.

Para a identificação das macroalgas não calcificadas foram utilizados os métodos convencionais de estudos ficológicos (Horta 2000). Para a identificação das coralináceas não articuladas (Corallinales, Rhodophyta) foi adotada a metodologia sintetizada por Horta (2002), enquanto que para as articuladas os métodos propostos por Moura (2000). As macroalgas foram enquadradas no sistema nomenclatural proposto por Wynne (2005). Os organismos, quando tratados de maneira geral, foram referidos como UTOs (Unidades Taxonômicas Operacionais), termo originalmente cunhado por Sneath \& Sokal (1973) para denominar as unidades objeto da análise. Atualmente o termo é universalmente utilizado para denominar os táxons terminais de uma árvore, podendo estes ser indivíduos, populações, espécies, gêneros, famílias, etc. (do inglês OTU = Operational Taxonomic Unit). Nos estudos de estrutura de comunidades espécimes dos gêneros Polysiphonia e Neosiphonia quando presentes em tufos agregados foram considerados como representantes de um complexo denominado Polysiphonia. Os espécimes analisados e as lâminas produzidas para a identificação foram depositados no herbário da Universidade Federal de Santa Catarina (FLOR).

\section{ANÁLISE DOS DADOS}

Os dados foram analisados segundo as médias aritméticas acompanhadas dos respectivos erros padrões, sendo calculados para cada amostra os descritores de riqueza específica e diversidade de Shannon-Hill. A partir dos dados brutos de biomassa, com 71 amostras e 74 espécies, transformadas $(\log (x+1))$, foi calculado o índice de similaridade de Bray-Curtis e processada a Análise de Escalonamento Multidimensional (MDS). Eventuais significâncias de diferenças observadas entre os valores similaridade, segundo os fatores tipo de substrato, grau de exposição e profundidades, foram verificadas utilizando-se a análise ANOSIN $(p<0,05)$. A referida análise, assim como os descritores sintéticos simples e complexos, foi calculada com o auxílio do aplicativo PRIMER 5.0.

Utilizando-se o programa Statistica 6.0 a análise ANOVA unifatorial, seguida do teste de Tukey, foi utilizada para testar a significância $(\mathrm{p}<0,05)$ das diferenças entre as médias dos diferentes descritores entre as diferentes áreas amostrais. A homogeneidade das variâncias foi verificada pelo teste de Cochran assumindo-se os dados como independentes (Zar 1996). Para a apresentação gráfica os valores médios e respectivas medidas de dispersão (erro padrão), calculados em relação aos elementos amostrais para cada estação amostral foram transformados em gramas por $\mathrm{m}^{2}$. Optou-se por este procedimento a fim de facilitar eventuais comparações com outros trabalhos que eventualmente utilizaram elementos amostrais de tamanhos diferentes. Tal estratégia é freqüentemente verificada na literatura como, por exemplo, nos trabalhos de Amado Filho et al. (2003, 2006).

\section{RESULTADOS}

\section{CARACTERIZAÇÃO DAS ESTAÇÕES AMOSTRAIS}

As três ilhas apresentam relevo extremamente acidentado com profundidades variando de 5 a $18 \mathrm{~m}$. $\mathrm{Na}$ Ilha das Gales as coletas foram realizadas em três estações. Do lado protegido, voltado para oeste, amostrou-se a Toca da Salema, região central da Ilha e a Ponta Norte. Na Tocada da Salema o substrato não consolidado, encontrado de 12 a $10 \mathrm{~m}$ de profundidade, caracterizou-se por um sedimento biodetrítico 
grosseiro recoberto por algas calcárias incrustantes, apresentando uma diversificada e abundante comunidade epibionte dominada por macroalgas filamentosas. O substrato consolidado, presente a partir dos $10 \mathrm{~m}$ de profundidade, caracterizou-se por uma combinação de matacões grandes e pequenos oferecendo uma elevada heterogeneidade de nichos. $\mathrm{Na}$ Ponta Norte da referida Ilha o substrato não consolidado, encontrado de 12 a $10 \mathrm{~m}$ de profundidade, caracterizou-se por um sedimento areno-lodoso, apresentando epibiontes utilizando como substrato conchas e fragmentos de pedras dispersos. O substrato consolidado, presente a partir dos $10 \mathrm{~m}$ de profundidade, caracterizou-se pela presença de matacões grandes oferecendo uma heterogeneidade de nichos moderada. Do lado exposto, voltado para leste, coletou-se no Saco da Mulata, pequena enseada na porção central. Observou-se grande movimentação de fundo, que pode ser caracterizado pela presença de grandes matacões. Deve-se destacar que a transparência na referida Ilha foi a menor entre as áreas amostradas.

A Ilha do Arvoredo apresenta-se de forma geral como uma área com elevada heterogeneidade de nichos com substrato consolidado em áreas geralmente mais profundas, abrigando uma flora abundante e diversificada. A Enseada do Farol destacou-se por apresentar elevada diversidade com substrato formado por matacões grandes nas profundidades de 18 a $13 \mathrm{~m}$. Já, nas profundidades de 12 a $4 \mathrm{~m}$ observou-se matacões grandes e médios proporcionando uma heterogeneidade de nichos moderada. O Banco de nódulos calcários apresentou-se constituído principalmente pelas espécies formadoras de nódulos Lithothamnion heteromorphum e Mesophyllum erubescens. No Rancho Norte e Saco d'Água o substrato se caracterizou por matacões grandes de heterogeneidade de nichos moderada, com fundo não consolidado desprovido de flora macroalgal. A transparência da água na referida Ilha foi maior do que a observada na Ilha das Galés.

A Ilha Deserta apresentou relevo acidentado, elevada heterogeneidade de substrato e uma transparência da água relativamente maior que as outras áreas amostradas. Nesta localidade o substrato rochoso iniciou aos $12 \mathrm{~m}$ sendo constituído por matacões grandes e médios.

\section{ASPECTOS TAXONÔMICOS}

Foram identificados 127 táxons infragenéricos sendo estes representados por 95 Rhodophyta, 17 Phaeophyceae, 14 Chlorophyta e um (1) Cyanophyta. Desses 127 taxons, 113 foram encontrados em costões rochosos, sendo 79 táxons exclusivos para este ambiente, e 48 encontrados sobre o ambiente estruturado pelo banco de algas calcárias, com 14 táxons exclusivos (Figura 1).

Dentre todos os grupos destacam-se as Ceramiales com 41 táxons, sendo que a espécie mais
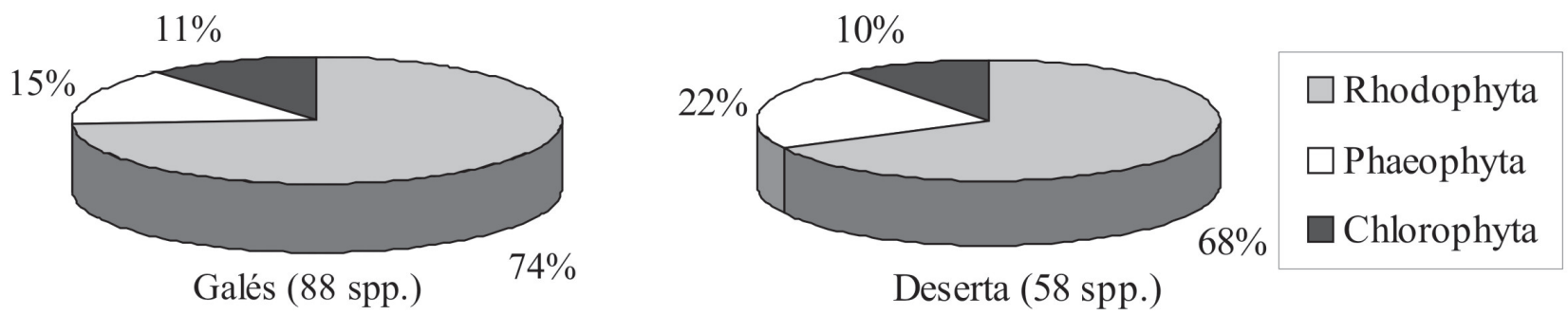

Deserta (58 spp.)

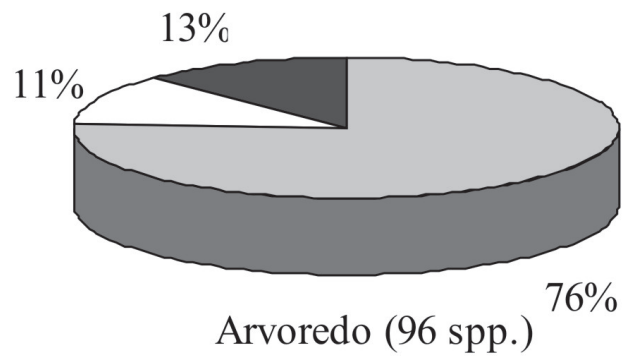

Figura 2. Contribuição percentual dos grupos Rhodophyta, Phaeophyceae e Chorophyta em cada ilha amostrada e números de táxons encontrados em cada uma das referidas localidades (Arvoredo $\mathrm{n}=38$; Galés $\mathrm{n}=21$; Deserta $\mathrm{n}=12$ ).

Figure 2. Relative percentage of each algae class Rhodophyta, Phaeophyceae, and Chorophyta found in each sampled island. The actual number of taxa found is given in parenthesis. (Arvoredo $n=38$; Galés $n=21$; Deserta $n=12$ ). 
freqüente, que esteve presente em praticamente todas as áreas amostradas, foi Asparagopsis taxiformis (fase tetrasporofítica). Para a Ilha Deserta foram identificados 58 táxons infragenéricos, para o Arvoredo 96 e para as Galés 88. Destes totais, de maneira semelhante para as três ilhas, cerca de $70 \%$ das espécies foram algas vermelhas e $10 \%$ algas verdes. A representação das algas pardas foi sensivelmente maior na Ilha Deserta, onde estas representaram cerca de $20 \%$ das espécies identificadas (Figura 2).

\section{ASPECTOS ECOLÓGICOS}

O Tapete (turf) de algas foi uma das UTOs mais freqüentes, tendo sua composição variando entre as amostras analisadas, e sendo composta por um ou mais dos seguintes táxons: Haliptilon cubense, Jania adhaerens, Amphiroa beauvoisii, Aglaothamnion spp, Asparagopsis taxiformis (fase tetrasporofítica), Ceramium spp., Compsothamnion thuyoides, Herposiphonia secunda, Heterosiphonia crispella e representantes do complexo Polysiphonia.

A espécie Sargassum vulgare apresentou maior biomassa determinando a fisionomia de boa parte das áreas visitadas, sendo responsável por $41,5 \%$ $\left(36,73 \mathrm{~g} \cdot \mathrm{m}^{-2} \pm 5,83\right)$ da biomassa média encontrada para todas as ilhas, seguida de Peyssonnelia capensis com 17,5\% (15,50g. $\left.\mathrm{m}^{-2} \pm 6,89\right)$, Padina gymnospora com 9,8\% $\left(8,66 \mathrm{~g} \cdot \mathrm{m}^{-2} \pm 2,48\right)$ e Amphiroa beauvoisii com $8,8 \%\left(5,28 \mathrm{~g} \cdot \mathrm{m}^{-2} \pm 2,19\right.$; Figura 3$)$.

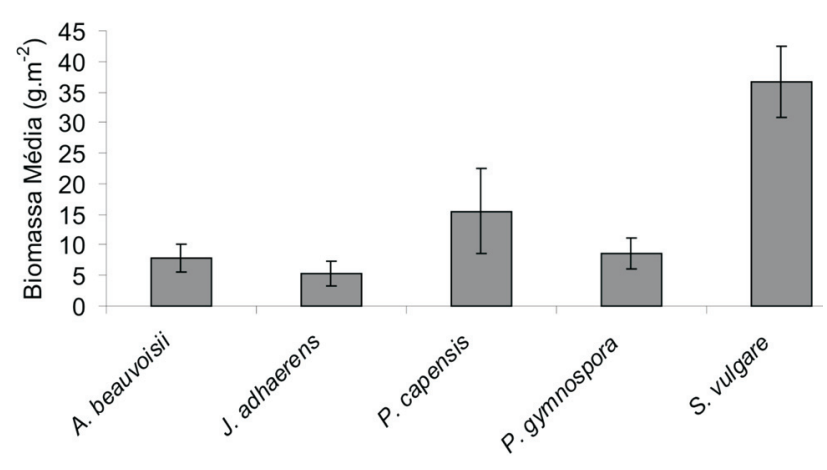

Figura 3. Espécies de macroalgas que apresentaram mais de $5 \%$ da biomassa média encontrada nas áreas amostrais $(A$. beauvoisii $=$ Amphiroa beauvoisii $J$. adhaerens $=$ Jania adaerens $;$ P. capensis $=$ Peyssonnelia capensis $;$ P. gymnospora $=$ Padina gymnospora e $S$. vulgare $=$ Sargassum vulgare. Medida de dispersão= erro padrão, $\mathrm{n}=71$ ).

Figure 3. Macroalgae species composing over 5\% of the mean sampled

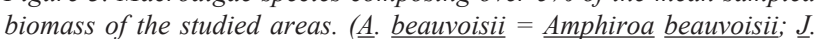

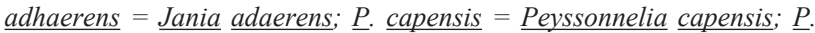
$\underline{\text { gymnospora }}=\underline{\text { Padina gymnospora and } \underline{\text { S }} \text { vulgare }}=\underline{\text { Sargassum }} \underline{\text { vulgare }}$. Vertical lines represent standard error; $n=71$.
Considerando os valores médios, a biomassa geral (a soma de todos os táxons de cada amostra) encontrada nos costões rochosos da Ilha do Arvoredo (156,25g.m$\left.{ }^{2} \pm 15,09\right)$ foi significativamente maior (ANOVA, $\mathrm{p}<0,05 ; \mathrm{F}=2,42)$ que na Ilha Deserta $(123,66 \mathrm{~g} . \mathrm{m}$ $\left.{ }^{2} \pm 16,64\right)$ e nas Galés $\left(47,55 \mathrm{~g} \cdot \mathrm{m}^{-2} \pm 7,42\right)$ (Figura 4).

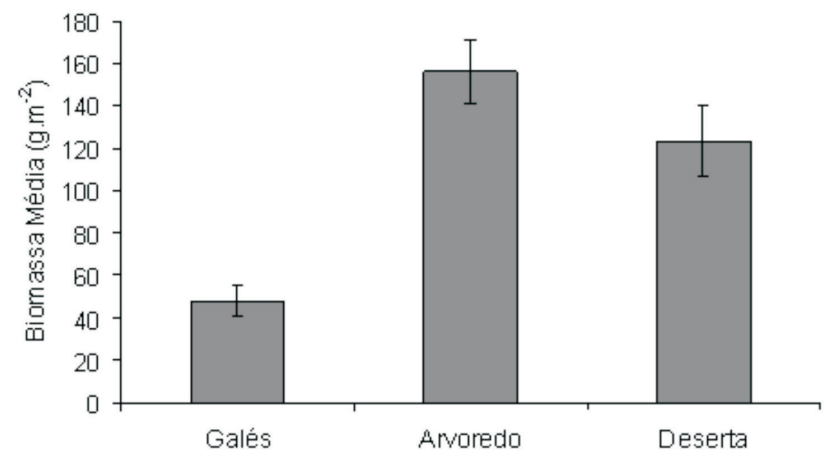

Figura 4. Biomassa total encontrada nas Ilhas do Arvoredo ( $n=38)$, Galés $(\mathrm{n}=21)$ e Deserta $(\mathrm{n}=12)$ (medida de dispersão= erro padrão).

Figure 4. Total biomass found in Arvoredo $(n=38)$, Galés $(n=21)$, and Deserta $(n=12)$ island. Vertical lines represent standard error.

Na Ilha das Galés, a estação Toca da Salema apresentou sobre o substrato não consolidado sedimento biodetrítico grosseiro recoberto por algas calcárias incrustantes, apresentando diversificada e abundante comunidade epibionte, com predominância de macroalgas como Ceramium luetzelburgii $\left(4,06 \mathrm{~g} \cdot \mathrm{m}^{-2} \pm 1,64\right)$, Gracilaria tepocensis $\left(3,14 \mathrm{~g} \cdot \mathrm{m}^{-}\right.$ $\left.{ }^{2} \pm 3,13\right)$ ediferentes espécies do complexo Polysiphonia (Figura 5). Sobre o substrato consolidado a espécie $S$. vulgare destacou-se de forma marcante com cerca de $26 \mathrm{~g} \cdot \mathrm{m}^{-2}( \pm 10,76)$. Associadas ao $S$. vulgare ocorreram $P$. gymnospora com $3,47 \mathrm{~g} . \mathrm{m}^{-2}( \pm 1,41), A$. beauvoisii com $2,77 \mathrm{~g} \cdot \mathrm{m}^{-2}( \pm 0,98)$ e Pleonosporium mexicanum com $1,45 \mathrm{~g} \cdot \mathrm{m}^{-2}( \pm 1,45)$ (Figura 6). $\mathrm{Na}$ segunda estação, a Ponta Norte da referida Ilha, o substrato não consolidado (profundidades entre $14 \mathrm{e}$ $11 \mathrm{~m}$ ) caracterizou-se por um sedimento areno-lodoso, apresentando epibiontes como Neosiphonia ferulacea $\left(2,76 \mathrm{~g} \cdot \mathrm{m}^{-2} \pm 1,82\right)$, G. tepocensis $\left(0,70 \mathrm{~g} \cdot \mathrm{m}^{-2} \pm 0,34\right) \mathrm{e}$ Hypnea spinella $\left(0,40 \mathrm{~g} \cdot \mathrm{m}^{-2} \pm 0,10\right)$, utilizando como substrato conchas e fragmentos dispersos de pedras (Figura 7). O substrato consolidado (profundidades inferiores a $10 \mathrm{~m}$ ) caracterizou-se pela presença da população de Sargassum vulgare com 55,12g.m ${ }^{-2}$ $( \pm 17,99)$, associada à Rhodymenia pseudopalmata $\left(4,51 \mathrm{~g} \cdot \mathrm{m}^{-2} \pm 2,39\right), P$. gymnospora $\left(2,14 \mathrm{~g} \cdot \mathrm{m}^{-2} \pm 1,14\right) \mathrm{e}$ Gelidium pusillum $\left(1,00 \mathrm{~g} \cdot \mathrm{m}^{-2} \pm 0,81\right)$ (Figura 8 ). Do lado exposto (voltado para leste, no Saco da Mulata) 
sobre o substrato consolidado observou-se uma fisionomia caracterizada por $P$. gymnospora com $19,71 \mathrm{~g} \cdot \mathrm{m}^{-2}( \pm 12,01)$, seguida de S. vulgare $(17,75$ g.m $\left.\mathrm{m}^{-2} \pm 3,13\right)$, ocorrendo em manchas descontínuas (Figura 9).

Na Ilha do Arvoredo destacou-se o predomínio de S. vulgare seguido por P. gymnospora, A. beauvoisii, Lobophora variegata, Jania adhaerens e $P$. capensis. Estas duas últimas espécies consideradas abundantes, porém, mais concentradas em pontos específicos como o costão do Rancho Norte e nas áreas mais profundas do Saco do Farol, respectivamente.

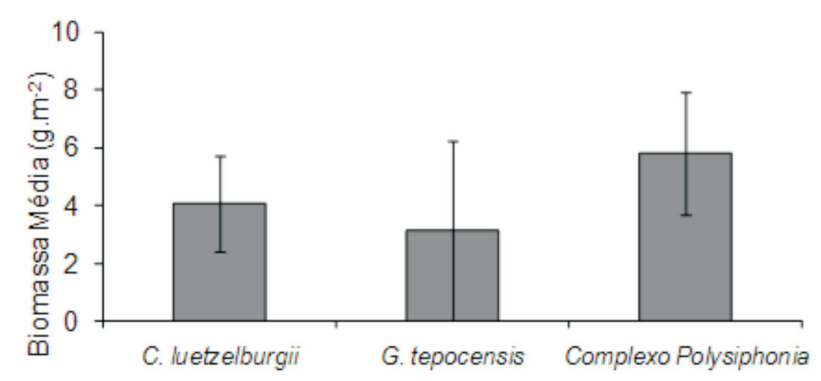

Figura 5. Macroalgas epibiontes sobre o sedimento inconsolidado da área amostral Toca da Salema, Ilha das Galés $(C$. luetzelburgii $=$ Ceramium luetzelburgii; $G$. tepocensis = Gracilaria tepocensis e complexo Polysiphonia $=$ grupo formado por espécies dos gêneros Polysiphonia $\mathrm{e}$ Neosiphonia. . Medida de dispersão= erro padrão, $\mathrm{n}=4$ ).

Figure 5. Epibiont macroalgae found over the inconsolidated sediments of Toca da Salema, Galés Island ( $\underline{\text { C. }}$ luetzelburgii $=\underline{\text { Ceramium }} \underline{\text { luetzelburgii, }}$ $\underline{G} . \underline{\text { tepocensis }}=\underline{\text { Gracilaria }} \underline{\text { tepocensis e complexo } \underline{\text { Polysiphonia }}=\text { group }}$ formed by Polysiphonia e Neosiphonia). Vertical lines represent standard error; $n=4$.

O Saco do Farol destacou-se por apresentar uma grande disponibilidade de substrato que se estendia por dezenas de metros em uma declividade suave. A $15 \mathrm{~m}$ de profundidade observou-se o predomínio de $P$. capensis com $229,07 \mathrm{~g} . \mathrm{m}^{-2}( \pm 53,64)$. A $10 \mathrm{~m}$ observa-se a ocorrência de um banco de $S$. vulgare com $54,51 \mathrm{~g} \cdot \mathrm{m}^{-2}( \pm 16,81)$ associado à $A$. beuvoisii com $48,41 \mathrm{~g} \cdot \mathrm{m}^{-2}( \pm 14,89)$. Nas áreas mais rasas $(5 \mathrm{~m})$ o predomínio da espécie $S$. vulgare é evidente, apresentando uma biomassa de $105,00 \mathrm{~g} \cdot \mathrm{m}^{-2}( \pm 59,33)$ (Figura 10).

O Banco de nódulos calcários apresenta-se como uma formação atípica no contexto da reserva e do litoral sul brasileiro, com composição e estrutura próprias. Dentre as algas calcárias estruturadoras desta biocenose destacaram-se as espécies Lithothamnion heteromorphum e Mesophyllum erubescens. Dentre as espécies epibiontes destacaram-se Dictyota pulchella com $9,92 \mathrm{~g} \cdot \mathrm{m}^{-2}( \pm 2,65)$ aos $5 \mathrm{~m}$, a fase tetrasporofítica de Asparagopsis taxiformis 9,70g. $\mathrm{m}^{-2}( \pm 2,90)$ aos $10 \mathrm{~m}$ e Sebdenia flabellata $\left(2,60 \mathrm{~g} \cdot \mathrm{m}^{-2} \pm 2,6\right)$ aos $15 \mathrm{~m}$ (Figura 11).

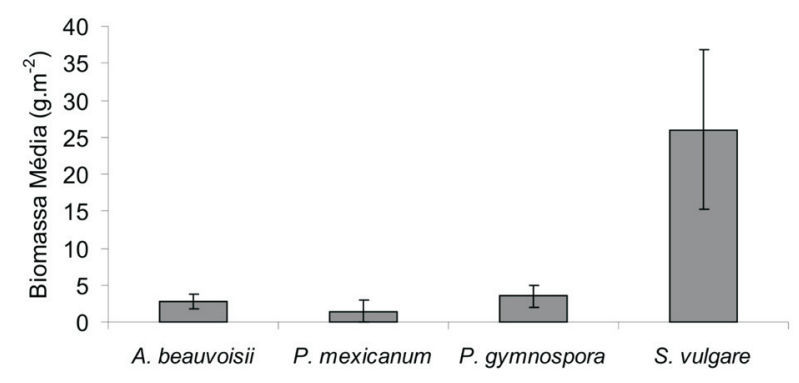

Figura 6. Macroalgas dominantes no costão rochoso (substrato consolidado) da área amostral Toca da Salema, Ilha das Galés (A. beauvoisii $=$ Amphiroa beauvoisii $;$. mexicanum $=$ Pleonosporium mexicanum $; P$ gymnospora $=$ Padina gymnospora e $S$. vulgare = Sargassum vulgare . Medida de dispersão= erro padrão, $\mathrm{n}=5$ ).

Figure 6: Dominant macroalgae found over the rocky shores (consolidated sediment) of Toca da Salema, Galés Island ( $\underline{\text { A }}$ beauvoisii $=\underline{\text { Amphiroa }}$

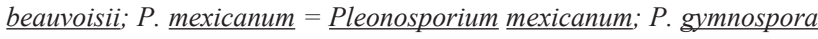

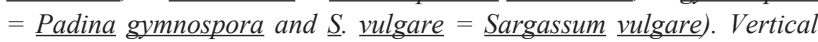
lines represent standard error; $n=5$.

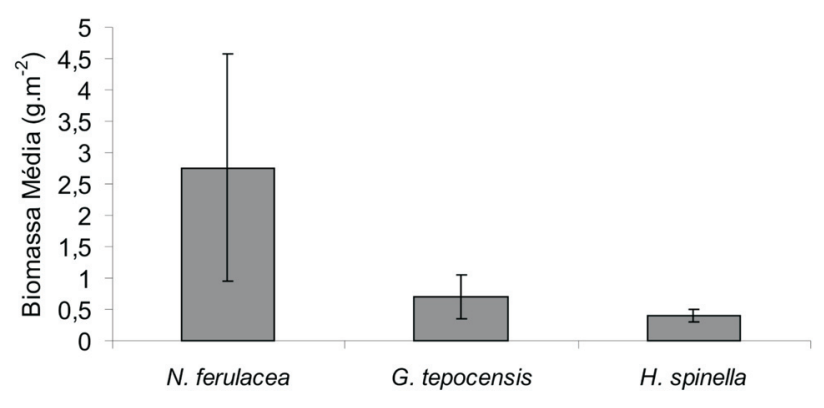

Figura 7. Biomassa das macroalgas epibiontes sobre o sedimento inconsolidado na área amostral Ponta Norte, Ilha das Galés $(N$. ferulacea $=$ Neosiphonia ferulacea; G. tepocensis = Gracilaria tepocensis e $H$. spinella = Hypnea spinella . Medida de dispersão = erro padrão, $\mathrm{n}=3$ ).

Figure 7. Epibiont macroalgae biomass found over the inconsolidated sediments of Ponta Norte, Galés Island. (N. ferulacea $=\underline{\text { Neosiphonia }}$ ferulacea; $G$. $\underline{\text { tepocensis }}=\underline{\text { Gracilaria }} \underline{\text { tepocensis }}$ and $H . \underline{\text { spinella }}=$ Hypnea spinella). Vertical lines represent standard error; $n=3$.

Tanto a área amostrada do costão do Saco d'Água quanto do Rancho Norte apresentaram o fitobentos composto por uma população de $S$. vulgare, com respectivamente $11,55( \pm 5,43) \mathrm{e}$ $44,99 \mathrm{~g} \cdot \mathrm{m}^{-2}( \pm 23,70)$ acompanhado por $L$. variegata $\left(14,26 \mathrm{~g} \cdot \mathrm{m}^{-2} \pm 6,44\right)$ e $A$. beauvoisii $\left(8,21 \mathrm{~g} \cdot \mathrm{m}^{-2} \pm 5,59\right)$ no Saco d'Água. P. gymnospora $\left(54,75 \mathrm{~g} . \mathrm{m}^{-}\right.$ $\left.{ }^{2} \pm 23,70\right)$ e $J$. adhaerens $\left(46,92 \mathrm{~g} \cdot \mathrm{m}^{-2} \pm 23,08\right)$ no Rancho Norte (Figura 12).

A estrutura observada nas amostragens entre a Porção Norte (exposta) e Porção Central (protegida) 
na Ilha Deserta são similares. No entanto, o costão considerado abrigado, de modo geral, apresentou os maiores valores de biomassa média para as algas dominantes, como S. vulgare $\left(105,45 \mathrm{~g} \cdot \mathrm{m}^{-2} \pm 6,69\right)$, P. gymnospora $\left(35,23 \mathrm{~g} \cdot \mathrm{m}^{-2} \pm 9,00\right)$, A. beauvoisii $\left(13,01 \mathrm{~g} \cdot \mathrm{m}^{-2} \pm 6,84\right)$ e $J$. adhaerens $\left(7,17 \mathrm{~g} \cdot \mathrm{m}^{-2} \pm 6,07\right)$ (Figura 13).

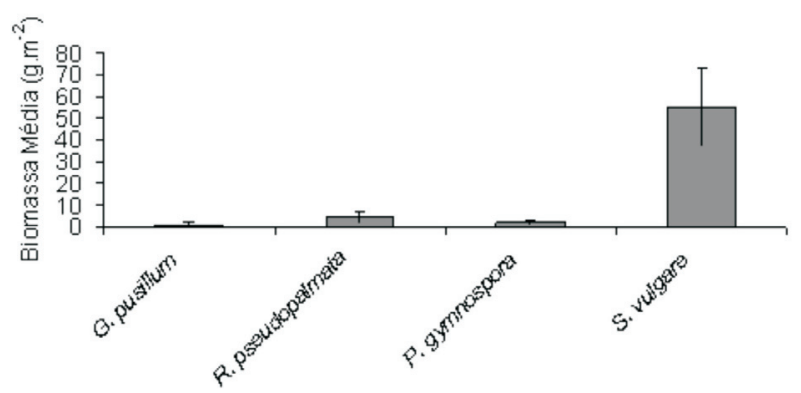

Figura 8. Biomassa das macroalgas dominantes do costão rochoso (substrato consolidado) da área amostral Ponta Norte, Ilha das Galés ( $G$. pusilum $=$ Gelidium pusilum $;$ R. pseudopalmata $=$ Rhodymenia pseudopalmata $;$ P. gymnospora = Padina gymnospora e $S$. vulgare = Sargassum vulgare. Medida de dispersão = erro padrão, $\mathrm{n}=6$ ).

Figure 8. Biomass of the dominant macroalgae found over the rocky shores (consolidated sediment) of Ponta Norte, Galés Island. ( $\underline{G}$. pusilum

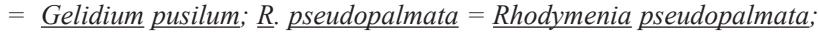
$\underline{P}$. gymnospora $=\underline{\text { Padina gymnospora }}$ and $\underline{S}$. $\underline{\text { vulgare }}=\underline{\text { Sargassum }}$ vulgare). Vertical lines represent standard error; $n=6$.

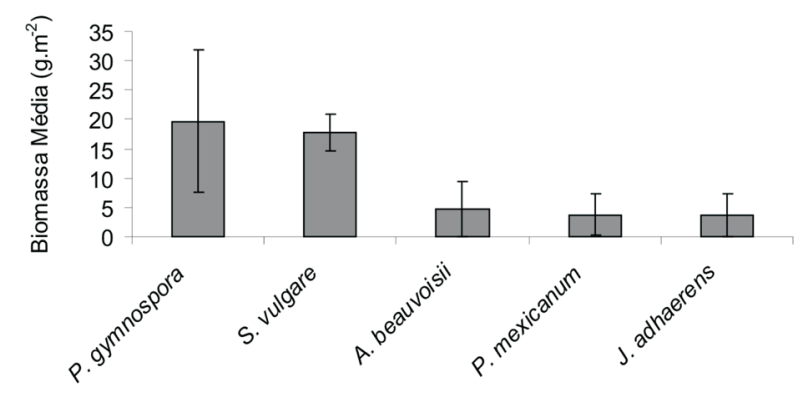

Figura 9. Biomassa das macroalgas que apresentaram mais que 5\% na contribuição em biomassa do lado exposto no Saco da Mulata, Porção central Ilha das Galés $(P$. gymnospora = Padina gymnospora; $S$. vulgare = Sargassum vulgare; A. beauvoisii $=$ Amphiroa beauvoisii $;$ P. mexicanum $=$ Pleonosporium mexicanum e $J$. adhaerens $=$ Jania adaerens. Medida de dispersão = erro padrão, $\mathrm{n}=3$ ).

Figure 9. Biomass of the macroalgae species that composed over 5\% of the mean sampled biomass of the exposed side of Saco da Mulata, in the middle of Gales Island ( $\underline{P}$. gymnospora $=\underline{\text { Padina gymnospora; }}$ $\underline{S} . \underline{\text { vulgare }}=\underline{\text { Sargassum vulgare }} ; \underline{\text { A. }} . \underline{\text { beauvoisii }}=\underline{\text { Amphiroa }} \underline{\text { beauvoisii }} ;$

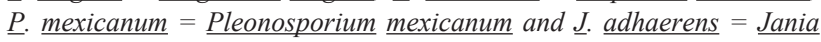
adaerens). Vertical lines represent standard error; $n=3$.

Assim como observado para a biomassa geral, a biomassa de Sargassum vulgare foi significativamente maior nas Ilhas Arvoredo e Deserta que na Ilha das Galés (ANOVA, $\mathrm{p}<0,05 ; \mathrm{F}=3,46$ ). As demais espécies não foram comparadas por apresentarem distribuição irregular e participação, algumas vezes, pouco expressiva.

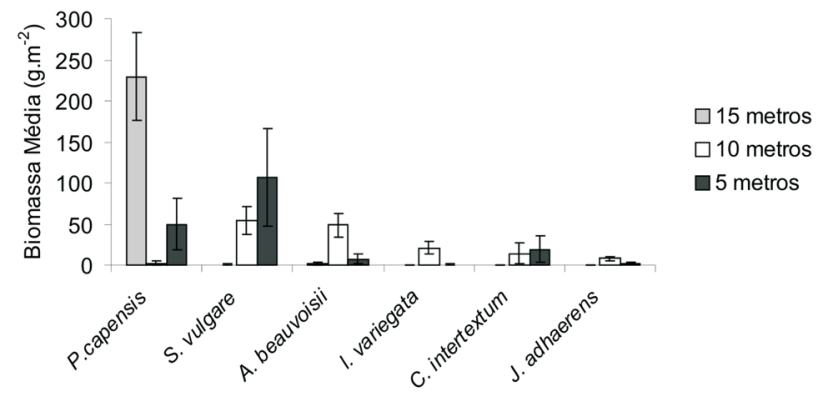

Figura 10. Biomassa média das macroalgas dominantes a $15(n=4)$, $10(\mathrm{n}=7)$ e $5(\mathrm{n}=4)$ metros de profundidade no Saco do Farol, Ilha do Arvoredo. (P. capensis $=$ Peyssonnelia capensis; S. vulgare $=$ Sargassum vulgare; A. beauvoisii = Amphiroa beauvoisii L. variegata $=$ Lobophora variegata; $C$. intertextum $=$ Codium intertextum e J. adhaerens $=$ Jania adhaerens. Medida de dispersão = erro padrão.

Figure 10. Mean biomass of the dominant macroalgae species found at $15 m(n=4), 10 m(n=7)$, and $5 m(n=4)$ deep at Saco do Farol, Arvoredo Island $(\underline{P} . \underline{\text { capensis }}=\underline{\text { Peyssonnelia }} \underline{\text { capensis }} ; \underline{\text { S. vulgare }}=\underline{\text { Sargassum }}$ vulgare; $\underline{\text { A }}$. beauvoisii $=\underline{\text { Amphiroa }}$ beauvoisii $; \underline{\text { L. variegata }}=\underline{\text { Lobophora }}$

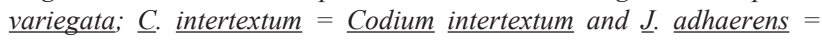

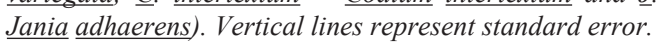

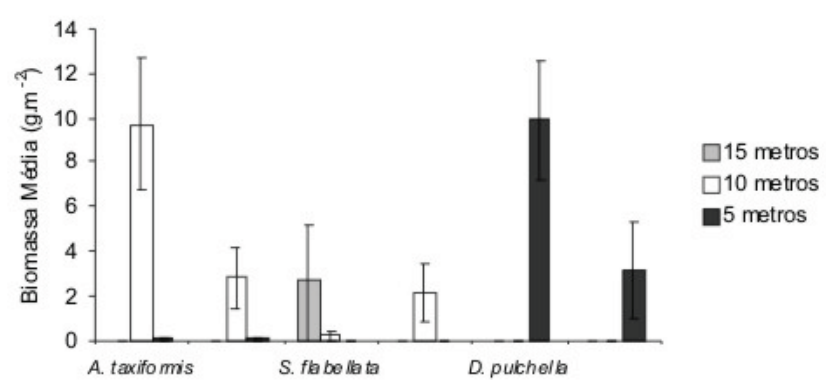

Figura 11. Biomassa média das macroalgas dominantes a $15(n=5), 10$ $(\mathrm{n}=5)$ e $5(\mathrm{n}=4)$ metros de profundidade presentes no Banco de Algas Calcárias, Ilha do Arvoredo (A. taxiformis = Asparagopsis taxiformis; $S$. flabellata $=$ Sebdenia flabellata e D. pulchella $=$ Dictyota pulchella $)$. Medida de dispersão= erro padrão.

Figure 11. Mean biomass of the dominant macroalgae species found at $15 m(n=4), 10 m(n=7)$, and $5 m(n=4)$ deep at the rhodolith bed, Arvoredo Island $(\underline{\text { A }}$ t $\underline{\text { taxiformis }}=\underline{\text { Asparagopsis }} \underline{\text { taxiformis }} ; \underline{\text { S. flabellata }}=\underline{\text { Sebdenia }}$ flabellata and $\underline{D}$. pulchella $=\underline{\text { Dictyota } \text { pulchella). Vertical lines represent }}$ standard error.

A Análise do Escalonamento Multidimensional (MDS) destaca algumas particularidades como a segregação das amostras das áreas mais profundas do Saco do Farol, dominado por Peyssonnelia, e as áreas rasas representantes do Banco de nódulos calcários (Figura 15). Por outro lado, quando as similaridades entre as ilhas são comparadas não são observadas diferenças significativas (ANOSIN, $p>0,05$ ), o que pode ser verificado pelo denso agrupamento de amostras de diferentes localidades. Dentre os fatores analisados, destaca-se o tipo de substrato como determinante da estrutura da comunidade, resultando em grupos significativamente distintos (ANOSIN, 
$\mathrm{p}<0,05)$. O substrato inconsolidado proporciona uma série de limitações à colonização resultando em uma composição relativamente semelhante àquelas da Ilha da Galés. Isto pode ser verificado pelo agrupamento das amostras das áreas mais profundas do Banco de nódulos calcários. Quando consideradas apenas as áreas onde foram realizadas amostragens estratificadas, observa-se que a profundidade resulta em um fator determinante na variação da estrutura da comunidade, o que pode ser evidenciado no Saco do Farol e mais nitidamente no Banco de Algas calcárias onde as três profundidades são claramente segregadas pelo MDS, sendo os grupos formados significativamente distintos (ANOSIN, $\mathrm{p}<0,05$ ).

Os índices de diversidade e riqueza apresentaram grande variação. Na Ilha das Galés foram observados os maiores valores de diversidade de Shannon chegando a 1,73 para a Ponta Norte sobre o substrato arenoso. Por outro lado, o referido índice apresentou valor igual a zero na área dominada por Peyssonnelia no Saco do Farol da Ilha do Arvoredo. Os valores de riqueza variaram de $6,6 \mathrm{sp}$. amostra $^{-1}$ no Banco de nódulos calcários a 20,8 sp.amostra ${ }^{-1}$ na Ponta Norte da Ilha Deserta (Figura 14). Para os referidos descritores não foram observadas diferenças significativas entre as estações amostrais de cada uma das ilhas.

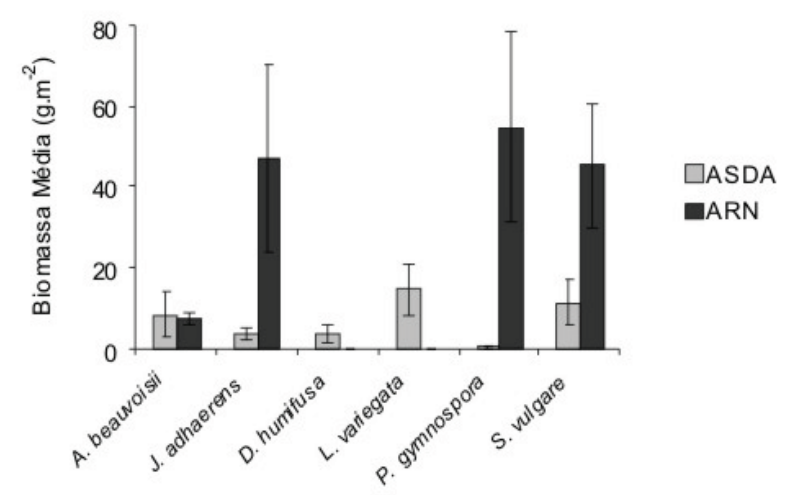

Figura 12. Biomassa média das macroalgas dominantes sobre o substrato consolidado nas estações ao norte da Ilha do Arvoredo (ASDA = Saco d'Água - costão direito e ARN = Rancho Norte; $A$. beauvoisii $=$ Amphiroa beauvoisii; J. adhaerens = Jania adhaerens; D. humifusa $=$ Dictyota humifusa; L. variegata $=$ Lobophora variegata; $P$. gymnospora = Padina gymnosposra e $S$. vulgare = Sargassum vulgare. Medida de dispersão= erro padrão).

Figure 12. Mean biomass of the dominant macroalgae species found over rocky bottom at the sampling sites to the north of Arvoredo Island (ASDA = Saco d'Água - right rocky shore $/ A R N=$ Rancho Norte; $A$. beauvoisi

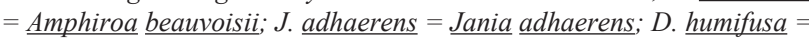
Dictyota humifusa; L. variegata $=$ Lobophora variegata; $P$. gymnospora

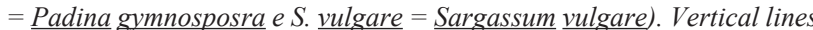
represent standard error.

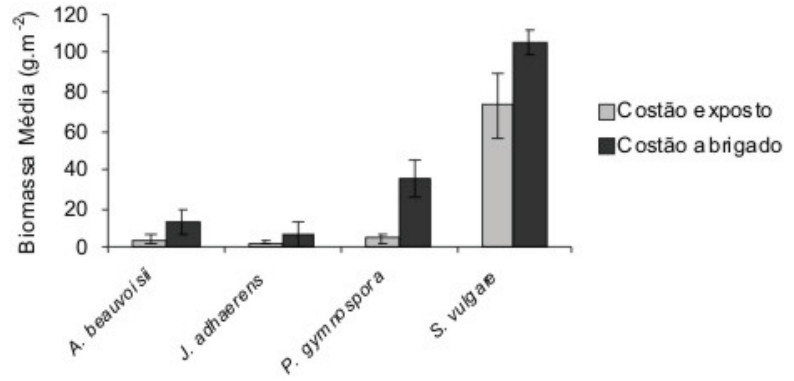

Figura 13. Biomassa média das macroalgas que ocorreram nos costões abrigado (Porção Central voltada para oeste, $n=5$ ) e exposto (Porção Norte voltada para leste, $\mathrm{n}=7$ ) da Ilha Deserta e que contribuíram com no mínimo $4 \%$ da biomassa em pelo menos um dos costões (A. beauvoisii $=$ Amphiroa beauvoisii $;$ J. adhaerens $=$ Jania adhaerens $;$ P. gymnospora = Padina gymnospora e $S$. vulgare = Sargassum vulgare. Medida de dispersão $=$ erro padrão).

Figure 13. Average biomass of the macroalgae species found on the sheltered rocky shores (Central portion facing west, $n=5$ ) and exposed rocky shores (North portion facing east, $n=7$ ) of Deserta Island, which composed at least $4 \%$ of the collected biomass of one of the rocky shores a (A. beauvoisii $=$ Amphiroa beauvoisii; J. adhaerens $=$ Jania adhaerens, $P$. gymnospora $=\underline{\text { Padina }}$ gymnospora and $S$. $\underline{\text { vulgare }}=\underline{\text { Sargassum }}$ vulgare). Vertical lines represent standard error.

\section{DISCUSSÃO}

\section{ASPECTOS QUALITATIVOS}

O infralitoral da Rebio do Arvoredo apresentou uma comunidade fitobêntica com um grande número de espécies, merecendo especial destaque algumas referências novas para a região sul do Brasil, como Asteromenia peltata, Dictyota humifusa, Myriogramme prostrata e Nitophyllum punctatum. Deve-se ressaltar que estas adições devem ser atribuídas ao fato de que o infralitoral da região de maneira geral é pouco conhecido. Sendo assim, outras áreas da mesma região têm o potencial de abrigar estas e outras adições, pois em sua maioria são algas típicas de regiões permanentemente submersas. Deve-se ainda destacar a presença de pelo menos uma possível espécie nova para a ciência. Esta é um representante do gênero Callophyllis. Estudos detalhados e novas coletas estão em andamento para uma adequada caracterização da referida espécie.

A flora do infralitoral da Rebio do Arvoredo apresentou-se bastante rica, podendo ser considerada como um ponto de alta diversidade quando comparado com outras localidades do litoral brasileiro. Utilizando semelhante método e esforço de coleta relativo à amostragem qualitativa, Horta (2000) considerou 


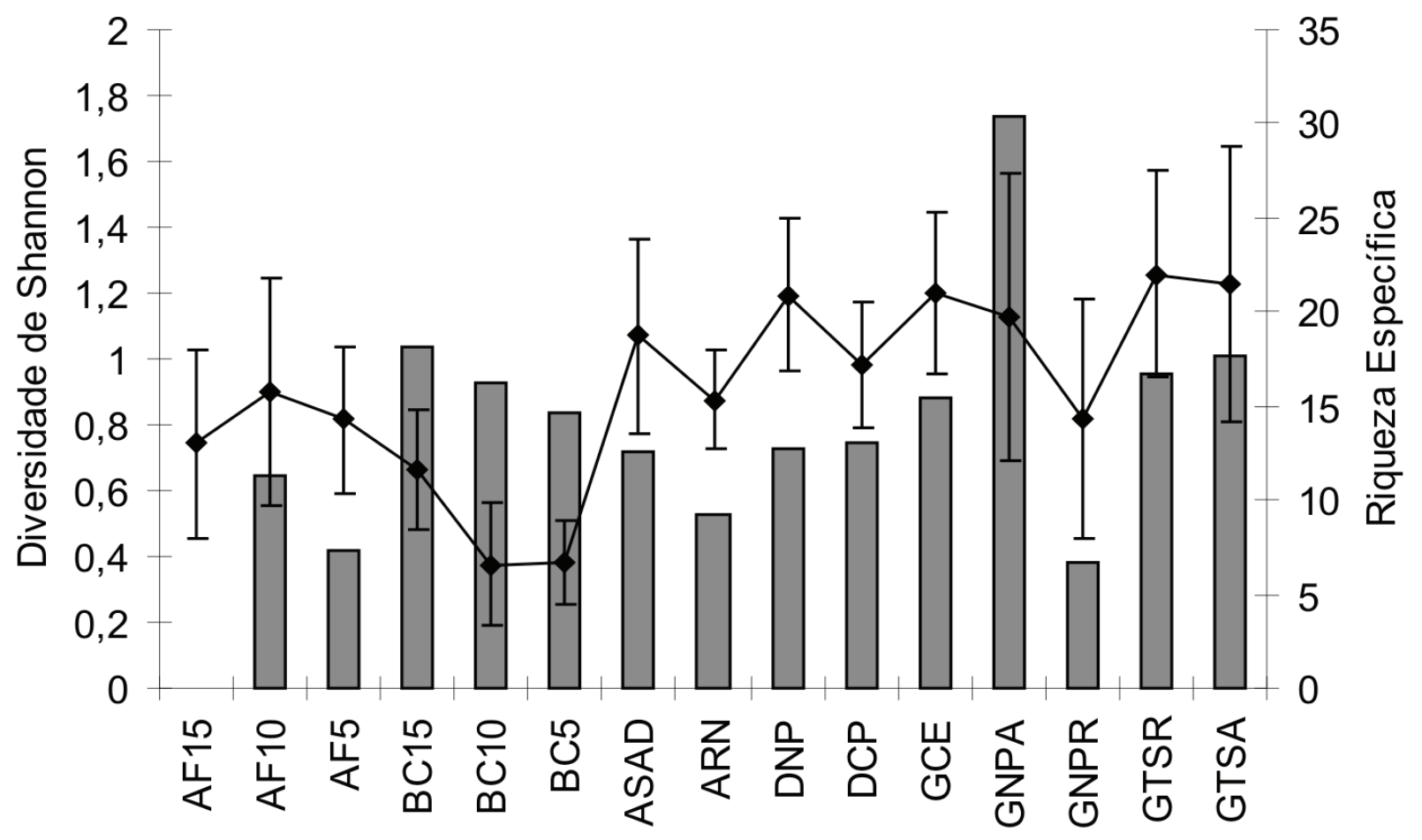

Figura 14. Médias da diversidade e riqueza nas diferentes estações, sendo na Ilha do Arvoredo: AF15, AF10 e AF5 - Saco do Farol a 15 ( $\mathrm{n}=4$ ), 10 $(n=7)$ e $5(n=4)$ metros de profundidade, respectivamente; e BC5, BC10 e BC15 - Banco de Algas Calcárias a $15(n=5), 10(n=5)$ e $5(n=4)$ metros de

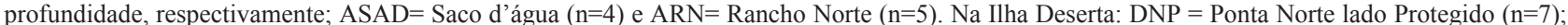
e DCP = Porção central lado Protegido $(n=5)$. Na Ilha das Galés: GCE - Porção central lado exposto (Saco da Mulata, $n=3$ ); GNPA = Ponta Norte do lado protegido em fundo arenoso $(n=3) ;$ GNPR = Ponta Norte do lado protegido em fundo rochoso ( $n=6)$; GTSA = Toca da Salema lado protegido em fundo arenoso $(\mathrm{n}=4)$; e GTSR $=$ Toca da Salema do exposto em fundo rochoso $(\mathrm{n}=5)$. (Medida de dispersão $=$ erro padrão).

Figure 14. Mean species diversity and richness in the different sampled stations. Arvoredo island: Saco do Farol-AF15, AF10, and AF5; Banco de Algas Calcarias - BC5, BC10 and BC15; ASAD=Saco d'água; ARN=Rancho Norte. Deserta island: DNP = Ponta Norte, sheltered side; DCP = central portion of the sheltered side. Gales island: GCE-central portion of the exposed side of Saco da Mulata; GNPA =north portion of the sheltered side, with sandy bottom; GNPR = north portion of the sheltered side, with rocky bottom; GTSA = sheltered side of Toca da Salema, with sandy bottom; GTSR = exposed side of Toca da Salema, with rocky bottom. Vertical lines represent standard error.

como 'hotspots' localidades com riqueza específica entre 50 e 70 táxons infragenéricos. Desta forma, considerando a riqueza encontrada para macroalgas, a localidade em questão com mais de 120 espécies deve ser considerada de grande relevância biológica. Deve-se destacar que esta diversidade representa cerca de $60 \%$ das espécies listadas para o infralitoral de toda a região sul e sudeste do Brasil e quase $20 \%$ de toda a flora de macroalgas brasileiras.

Entretanto, grande parte desta diversidade está representada por espécies diminutas, delicadas e, na maioria das vezes, filamentosas destacando-se a participação da ordem Ceramiales com mais de 30\% da composição específica. Dentre estas, destacou-se a presença de espécies típicas do sublitoral, como Compsothamnion thuyoides (Gorostiaga et al. 1998).

Quando comparada com outras áreas do infralitoral brasileiro, essa alta riqueza faz-se ainda mais expressiva. Para a região de Abrolhos (BA), por exemplo, Villaça \& Pitombo (1997) observaram 21 táxons pertencentes ao grupo das algas, incluindo Cyanobacterias.

Quando consideradas as comunidades algais de áreas da mesma província biogeográfica (Horta et al. 2001) a flora observada no presente estudo é bastante expressiva. Em Búzios (RJ), Oigman-Pszcol et al. (2004) encontraram 14 taxa de macroalgas (cinco Rhodophyta, quatro Phaeophyceae e cinco Chlorophyta), riqueza relativamente baixa se comparada com a encontrada na Rebio do Arvoredo (127 taxa).

No presente trabalho observou-se uma riqueza semelhante à encontrada no infralitoral Parque Estadual da Laje de Santos (129 táxons infragenéricos) no litoral Paulista por Amado Filho et al. (2006). Considerando que os referidos autores realizaram amostragens sazonais, pode-se estimar que se ampliando a escala temporal de caracterização, a Flora da Rebio do Arvoredo deve ser aumentada. 
Do ponto de vista fitogeográfico, tanto o índice de Cheney (1977) (Rhodophyta + Chlorophyta)/ Phaeophyta quanto o de Feldmann (1937) (Rhodophyta/Phaeophyta), apresentaram valores elevados (5,5 e 4,8; respectivamente) em relação ao que já era conhecido para a flora da região entre-marés da referida região biogeográfica (Horta et al. 2001). Tal resultado está de acordo com o observado para outras localidades no infralitoral de áreas temperadas quentes do litoral brasileiro (Horta 2000). Estes valores elevados dos índices mencionados são atribuídos a presença elevada de representantes das Rhodophyta no infralitoral, especialmente espécies filamentosas. Deve ainda ser destacada a presença de espécies típicas de regiões tropicais como Ernodesmis verticillata. Esta conjunção de algas típicas de regiões tropicais com algas típicas de regiões temperadas quentes (Gloiocladia iyoensis, Leptofauchea brasiliensis) é que dão ao infralitoral atribuições de zona de transição e contínuo já observada por Horta (2000).

\section{ASPECTOS QUANTITATIVOS}

Do ponto de vista da estrutura da comunidade a abundância de Sargassum observada no presente trabalho é semelhante à observada por Széchy (1996), Széchy \& Paula (2000) e Amado Filho et al. (2006). Entretanto, a faixa de distribuição de até $20 \mathrm{~m}$ de profundidade observada por Amado Filho et al. (2006) não foi observada na Rebio do Arvoredo, estando as áreas mais profundas ocupadas por espécies e comunidades com estruturas diferentes.

A variação na biomassa observada (Arvoredo $>$ Deserta $>$ Gales) combinada com a maior diversidade de organismos filamentosos na Ilha das Galés e Deserta pode ser explicada por uma distribuição variável de distúrbios (Connell 1978) produzidos por fatores como o hidrodinamismo, efluentes orgânicos e pressões diferenciadas de herbivoria (Thacker et al. 2001). Baseados nos dados e nas predições do referido modelo pode-se afirmar que as áreas amostradas na Ilha da Galés sofrem distúrbios mais freqüentes e/ou mais agudos que as demais ilhas visitadas. Estes distúrbios comprometeriam a estabilidade de sistemas onde uma única espécie dominante cederia lugar para espécies oportunistas de ciclo de vida rápido, como as algas filamentosas em questão. Os valores dos índices de diversidade estão inversamente relacionados com a abundância de espécies dominantes anteriormente descritas (Figura 14). A maior proximidade da Ilha das Galés a torna mais exposta aos impactos diretos e indiretos da urbanização da região costeira adjacente, como pode ser verificado através da menor transparência das águas, observado durante a amostragem. Entretanto esta hipótese deve ser testada em estudo específico através de caracterização detalhada da área de estudo e eventualmente através de uma abordagem experimental.

Assim como em áreas com formação recifal o substrato apresentou-se completamente coberto por organismos epibênticos sendo que, de maneira geral, a fisionomia do epibentos variou mais segundo fatores existentes dentro de cada uma das estações de coleta que entre as ilhas propriamente ditas. Este padrão pode ser ilustrado pelo teste de MDS onde se observou uma grande proximidade de amostras de diferentes estações de coleta (Figura 15). Esta relativa homogeneidade está relacionada com a presença das espécies Sargassum vulgare, Amphiroa beauvoisii e Jania adhaerens, que por sua vez determinaram a fisionomia nos diferentes localidades visitadas. Por outro lado áreas mais rasas assim como áreas de substrato arenoso apresentaram fisionomia particular (Figura 15).

Exceções a esta fisionomia podem ser verificadas de maneira marcante no Banco de nódulos calcários e na porção mais profunda do Saco do Farol, onde se observou o agrupamento de elementos dominados por Peyssonnelia capensis. Este constituinte da comunidade, por sua estratégia de ocupação do substrato, contribui para a redução da riqueza e da diversidade das respectivas áreas (Boudouresque 1973). Estes organismos tiveram Rebio sua ocorrência relacionada ainda com locais com baixa luminosidade ou frestas (Figura 10).

Os valores relativamente baixos dos índices de riqueza e diversidade podem ser atribuídos à presença de algas de grande porte, que por sua vez aumentam a dominância nos respectivos elementos amostrais diminuindo os valores dos índices (Figura 14). Estas algas frondosas podem ser ilustradas por Sargassum vulgare, Peyssonnelia capensis e Padina gymnospora, que devido a seu tamanho e estratégia de crescimento ocupavam grande parte do substrato.

Diferentemente de outras áreas recifais tropicais, onde os organismos dominantes muitas vezes são cnidários (Mussismilia brasiliensis e Palythoa 
cariboerum), a presente localidade se caracterizou pelo domínio marcante de macroalgas, destacando-se a participação dos bancos de Sargassum vulgare na estruturação dos diferentes ambientes. Esta comunidade apresenta valores de abundância compatíveis com outras áreas semelhantes, igualmente dominadas por espécies do gênero Sargassum (Széchy \& Paula 2000).
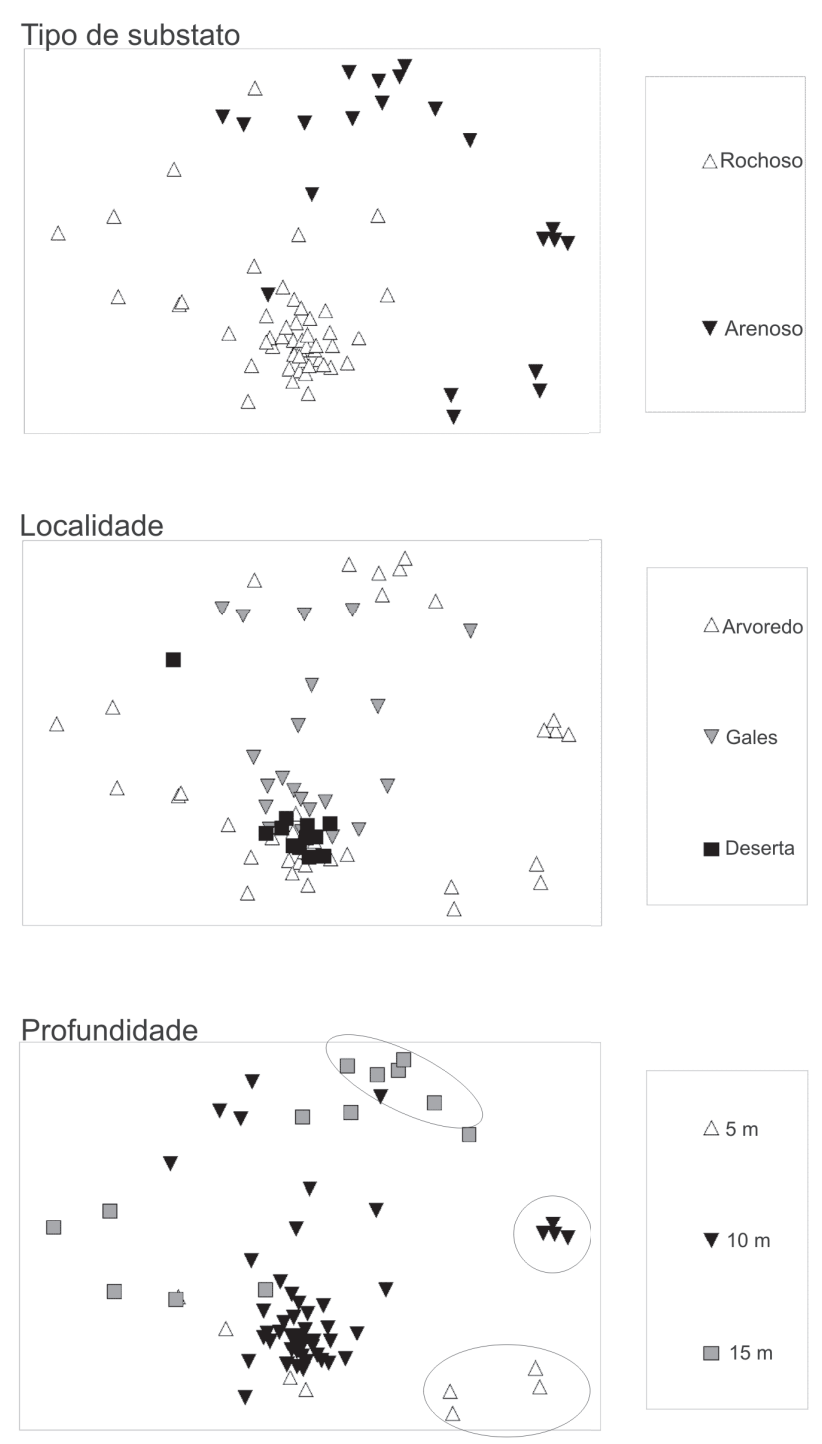

Figura 15. Análise do Escalonamento Multidimensional (MDS) das amostras do infralitoral da Rebio do Arvoredo, onde se evidencia o tipo de substrato, local de coleta e a profundidade das amostras, destacando-se nos círculos as amostras relativas ao banco de nódulos calcários. (Índice de Similaridade $=$ Bray-Curtis; $\mathrm{n}=71$; stress $=0,2$; os dados foram transformados usando-se $\log (\mathrm{x}+1)$ ).

Figure 15. Multidimensional Scaling (MDS) of the infralittoral samples from the Arvoredo Reserve. Type of substrate, sampling area and depth are presented separately. Circles indicate the samples from the banks of calcareous nodules. Similarity index was Bray-Curtis, $n=21$; stress $=0.2$; data were transformed with $\log (x+1)$.

Apesar de não terem sido incluídas na avaliação quantitativa, devido às limitações metodológicas, as algas calcárias incrustantes, em especial as espécies
Mesophyllum erubescens e Lithophyllum stictaeforme, se mostraram freqüentes na área de estudo. O referido grupo representa organismos construtores que fornecem substrato aumentando a heterogeneidade de microhábitats (Steneck 1997).

A baixa biomassa de algas observada sobre o banco de nódulos calcários pode estar relacionada a estratégia fisiológica deste grupo de algas em perder as camadas superficiais do epitalo como alternativa para controlar o epifitismo (Keats et al. 1994). Adicionalmente, a participação da ictiofauna e de herbívoros de pequeno porte (mesograzers) podem contribuir para o controle do epifitismo. A elevada heterogeneidade de nichos proporcionada pela estrutura dos nódulos favorece a coexistência destes organismos que, freqüentemente, estão representados por grupos diversos e abundantes (Steller et al. 2003). Steneck (1997) destaca que em ambientes infralitorâneos dominados por algas filamentosas as coralináceas incrustantes necessitam da presença de herbívoros para sua sobrevivência. Assim, em ambientes com alta herbivoria por peixes, ouriços e outros invertebrados, as coralináceas incrustantes tendem a ser dominantes.

\section{IMPLICAÇÕES PARA CONSERVAÇÃO}

A presença de tapetes de algas filamentosas recobrindo extensões razoáveis do banco de nódulos calcários e substrato não consolidado da Ilha das Galés (Ilha da Reserva mais próxima do litoral) pode representar um indício de impactos produzidos pela poluição por matéria orgânica com o respectivo aumento na disponibilidade de nutrientes (Thacker et al. 2001). Elevadas concentrações de nutrientes fosfatados atuam negativamente no metabolismo das algas calcárias (Bjork et al. 1995). Na hipótese de um eventual aumento da descarga costeira e poluição das áreas da reserva, o aumento nas concentrações de fosfatos pode levar à extinção todo o banco de nódulos calcários da referida reserva.

Trabalhos como o de McClanahan (1997), que comparou áreas protegidas e não protegidas em experimentos de sucessão algal em áreas recifais do Quênia, apontam uma grande diferença na composição das comunidades algais destas áreas, sendo que nas áreas protegidas a maior pressão de herbivoria por peixes permitiu um processo de sucessão e conseqüente esta- 
bilização da comunidade em cinco meses, enquanto nas áreas não protegidas houveram poucas mudanças durante todo o tempo de experimentação (450 dias) apesar das grandes variações ambientais promovidas por fatores sazonais na área de estudo. O mesmo trabalho aponta uma conseqüente dominância de turfs algais e uma menor diversidade de grupos funcionais nas áreas não protegidas, evidenciando a importância de uma proteção efetiva de áreas marinhas. Shears \& Babcock (2002) também demonstraram a importância das reservas marinhas em preservar o controle topdown da estrutura da comunidade em recifes da zona temperada, ao comparar áreas protegidas e não-protegidas da região nordeste da Nova Zelândia. Ao longo de um ano de experimentos de exclusão de ouriços, observaram a mudança de um ambiente caracterizado por algas calcárias crustosas para uma comunidade dominada por macroalgas não calcificadas. Essas comunidades de macroalgas haviam se apresentado mais expressivas nas áreas de reserva, onde a população de ouriços era menor. Os padrões observados demonstraram que reservas marinhas podem reverter efeitos indiretos da pesca e re-estabelecer a estrutura trófica dos ambientes.

Além dos fatores impactantes já citados nesse estudo, considerando a presença de organismos e populações endêmicas na área em questão, os eventuais impactos produzidos pela intensa atividade de mergulho na área da Reserva não deve ser desprezado. Embora não existam estudos para o litoral brasileiro, estudos realizados para o Mar Vermelho e Caribe comprovam a perda de biodiversidade das comunidades bênticas causada por atividades que envolvem mergulho autônomo recreativo e/ou profissional (Hawkins \& Roberts 1992, Dixon et al. 1993, Davis \& Tisdell 1996, Jameson et al. 1999). Desta forma, mesmo considerando que o mergulho autônomo representa uma importante ferramenta para um processo de educação ambiental que culmine na valorização da preservação dos recursos naturais, recomenda-se que providências sejam tomadas para limitar a referida prática à áreas fora dos limites da Rebio do Arvoredo.

Considerando ser a Rebio do Arvoredo a única em sua categoria em toda a província temperada quente do litoral brasileiro, recomenda-se que novas áreas insulares, assim como a Laje de Santos no litoral paulista, sejam avaliadas para que sejam criadas unidades de
Conservação igualmente restritivas. A existência de novas áreas igualmente preservadas poderá possibilitar o fluxo gênico entre estas comunidades, especialmente de espécies raras ou mesmo ameaçadas como destacado por Oliveira (2002), preservando este patrimônio para as gerações futuras.

AGRADECIMENTOS: Ao CNPq e ao MMA pelo financiamento concedido.

\section{REFERÊNCIAS}

AMADO-FILHO, G.M.;BARRETO, M.B.B.B.; MARINS, B.V.; FELIX,C \& REIS, R.P. 2003. Estrutura de comunidades fitobentônicas do infralitoral da Baía de Sepetiba, RJ, Brasil. Revista Brasileira de Botânica, 26: 329-342.

AMADO FILHO, G.M.; HORTA, P.A.; BRASILEIRO, P.S.; BARRETO, M.B.B. \& FUJII, M. T. 2006. Subtidal benthic marine algae of the Marine State Park of Laje de Santos (São Paulo, Brazil). Brazilian Journal of Oceanography, 54:1-21.

BJORK, M.; MOHAMMED, A.M.; BJÖRKLUND, M. \& SEMESI, A. 1995. Coralline algae, important coralreef builders threatened by pollution. Ambio, 24: 7-8.

BOUDOURESQUE, C.F. 1973. Recherches de bionomie analytique structurale et expérimentale sur les peuplements benthiques sciaphiles de Méditerranée occidentale (Fraction algale). Les peuplements sciaphiles de mode relativement calme sur substrats durs. Bulletin $d u$ Muséum d'Histoire Naturelle. Marseille, 33: 147-225

CASTRO, B.M. \& MIRANDA, L.B. 1998. Physical ocean-ography of the western atlantic continental shelf located between $4^{\circ} \mathrm{N}$ and $34^{\circ} \mathrm{S}$. In the sea (Robinson, A. R. \& Brink, K. H. eds.). p. 209-249.

CHAPIN III, F.S.; WALTER, B.H.; HOBBS, R.J.; HOOPER, D.U.; LAWTON, J.H.; SALA, O.E. \& TILMAN, D. 1997. Biotic control over the functioning of ecosystems. Science, 277: 500-504.

CHENEY, D.F. 1977. R+C/P, a new improved ratio for comparing seaweed floras. Journal of Phycology, 13 (supl.): 12.

CONNELL, J.H. 1978. Diversity in tropical rain forests and coral reefs. Science, 199:1302-1310.

CREED, J.C. 1997. Morphological variation in the seagrass Halodule wrightii near its southern distributional limit. Aquatic botany, 59: 163-172

CREED, J.C. \& AMADO FILHO, G.A. 1999. Disturbance and recovery of the macroflora of the seagrass (Halodule wrightii Ascherson) meadow in Abrolhos Marine National Park, Brazil: an experimental evaluation of anchor damage. Journal of Experimental marine Biology and Ecology, 235: 285-306.

DAVIS, D. \& TISDELL, C. 1996. Economic management of recreational SCUBA DIVING and the environment. Journal of Environmental Management, 48: 229-248. 
DIXON, J.A.; SCURA, L.F. \& VAN'T HOF, T. 1993. Meeting ecological and economic goals: Marine Parks in the Caribbean. Ambio, 22: 117-125.

ESTON, V.R. 1987. Zonação em costões rochosos: Infralitoral. Simp. Ecossist. Costa Sul Sudeste Bras. 1: 289-299.

ESTON, V.R. de; MIGOTTO, A.E.; OLIVEIRA FILHO, E.C.; RODRIGUES, S.A. \& FREITAS, J.C. 1986. Vertical distribution of benthic marine organisms on rocky coasts of the Fernando de Noronha archipelago (Brazil). Boletim do Instituto de Oceanografia de São Paulo, 34: 37-53.

FELDMANN, J. 1937. Recherches sur la végétation marine de la Méditerranée. La côte des Alberes. Revue Algologique, 10: 1-339.

FIGUEIREDO, M.A. de O. 1997. Colonization and growth of crustose coralline algae in Abrolhos, Brazil. Proceedings of the 8th International Coral Reef Symposium, 1: 689-693.

GOROSTIAGA, J.M.; SANTOLARIA, A.; SECILLA, A. \& DÍEZ, E. 1998 Sublittoral benthic vegetation of the eastern basque coas (N. Spain): structure and environmental factors. Botanica Marina, 41: 455-465.

HAWKINS, J.P. \& ROBERTS, C.P. 1992. Effects of recreational SCUBA diving on fore-reef slope communities of coral reefs. Biological Conservation, 26: 171-178.

HORTA, P.A. 2000. Macroalgas do infralitoral do sul e sudeste do Brasil: Taxonomia e Biogeografia. Instituto de Biociências (Tese de Doutorado).

HORTA, P. A. \& OLIVEIRA, E.C. 2001. Macroalgas del infralitoral - un nuevo desafio para el conocimiento de la biodiversidad marina brasilera. Pp 309-314. In: K. Alveal, T. Antezana. (Eds.) Sustentabilidad de la biodiversidad: un problema actual. Bases científico técnicas, teorizaciones y proyecciones Chile: Universidad de Concepción.

HORTA, P.A.; E. AMANCIO; C.S. COIMBRA, \& E.C. OLIVEIRA, 2001. Considerações sobre a distribuição e origem da flora de macroalgas marinhas brasileiras. Hoehnea, 28: 243-265.

HORTA, P.A. 2002. Bases para a identificação das coralináceas não articuladas do litoral brasileiro - uma síntese do conhecimento. Biotemas, 15: 7-44.

KEATS, D.W., WILTON P. \& MANEVELDT G. 1994. Ecological significance of deep-layer sloughing in the eulittoral zone coralline alga, Spongites yendoi (Foslie) Chamberlain (Corallinaceae, Rhodophyta) in South Africa. Journal of Experimental Marine Biology and Ecology, 175: 145-154.

JAMESON, S.C.; AMMAR, M.S.A.; SAADALLA, E.; MOSTAFA, H.M. \& RIEGL, B. 1999. A coral damage index and its application to diving sites in the Egyptian Red Sea. Coral Reefs, 18: 333-339.

MAGGS, C.A.; MILNER, A.A; WATTS, W. \& WHITTLE, M.R. 1979. The Oxford diving expedition to Cabo Frio, Brazil. Bulletin of Oxford University Exploration Club. New Series 4: 13-40

McCLANAHAN, T. R. 1997. Primary succession of coralreef algae: Differing patterns on fished versus unfished reefs. Journal of Experimental Marine Biology and Ecology, 218: 77-102.

MITCHELL, G.J.P.; MITSUYA, L.A.; SZECHI, M.T.M.; BLOISE, G.C.; TEIXEIRA, U.F. \& LACERDA, L.D. 1982. Interação Acanthophora-Sargassum em praia rochosa de Angra dos Reis, Brasil. Resumos do Simpósio Internacional "Algas: a energia do amanhã" (12-16 de julho, 1982). Inst. Oceanográfico da Universidade de São Paulo, S.P., Brasil.

MOURA, C.W. 2000. Coralináceas com genículo (Rhodophyta, Corallinales) do litoral do Brasil. Universidade de São Paulo. São Paulo. Tese de Doutorado em Ciências Biológicas (Botânica). 265p.

NORTON, T.A. \& MILBURN, J.A. 1972. Direct observations on the sublittoral marine algae of Argyll, Scotland. Hydrobiologia, 40: 55-68.

OIGMAN-PSZCOL, S.S.; FIGUEIREDO, M.A.O \& CREED, J.C. 2004. Distribution of benthic communities on the tropical rocky subtidal of Armação de Búzios, Southeastern Brazil. Marine Ecology, 25: 173-190.

OLIVEIRA, E.C.; HORTA, P.A.; AMANCIO, C.E. \& SANT' ANNA, C.L. 1999. Algas e angiospermas marinhas bênticas do litoral brasileiro. Versão do texto sobre Avaliação e ações prioritárias para a conservação da biodiversidade da zona costeira e marinha. MMA/FNMA/GEF. Campinas, BDT, Fundação André Tosello. http://www.bdt.fat.org.br/workshop/ costa/algas [20 de junho de 2001].

OLIVEIRA, E.C. 2002. Macroalgas marinhas da costa brasileira - estado do conhecimento, usos e conservação biológica. Pp 122-126. In: E.L. Araújo et. al. Biodiversidade, conservação e uso sustentável da flora do Brasil Recife: Sociedade Botânica do Brasil.

PAGLIOSA, P.R.; FONSECA, A. \& BARBOSA, F.A. 2006. Evidence of Systemic Changes in Trace Metal Concentrations in Subtropical Estuarine Sediments as a Result of Urbanization. Journal of Coastal Research, 39: 1078-1083.

PAGLIOSA, P.R. \& BARBOSA, F.A. 2006. Assessing the environment-benthic fauna coupling in protected and urban areas of southern Brazil. Biological Conservation, 129: 408-417.

PHILLIPS, J.A. 1998. Marine Conservation initiatives in Australia: Their relevance to the conservation of macroalgae. Botanica Marina, 41:95-103.

QUÉGE, N. 1988. Laminaria (Phaeophyta) no Brasil, Uma perspectiva econômica. Depto. de Botânica da Univ. de S. Paulo. (Dissertação de Mestrado). 230p.

SHEARS, N.T. \& BABCOCK, R.C. 2002. Marine reserves demonstrate top-down control of community structure on temperate reefs. Oecologia, 132: 131-142.

SNEATH, P.H.A. \& SOKAL, R.R. 1973. Numerical Taxonomy. Freeman, San Francisco.

STATSOFT. 2001. STATISTICA system reference. Statsoft Inc. Tulsa.

STELLER, D.L.; RIOSMENA-RODRIGUEZ, R.; FOSTER, M.S. \& ROBERTS, C.A. 2003. Rhodolith bed diversity in the Gulf of California: the importance 
of rhodolith structure and consequences of disturbance. Aquatic Conservation: Marine and Freshwater Ecosystems, 13: S5-S20.

STENECK, R.S. 1997. Crustose coralline, other algal functional groups, herbivores and sediments: complex interation along reef productivity gradients. Proceedings of the 8th International Coral Reef Symposium, 1: 695-700.

SZÉCHY, M.T.M. de. 1996. Estrutura de Bancos de Sargassum (Phaeophyta-Fucales) do litoral dos Estados do Rio Janeiro e São Paulo. Universidade de São Paulo. (Tese de Doutorado). 180p.

SZECHY, M.T. \& PAULA, E.J. 2000. Padrões estruturais quantitativos de bancos de Sargassum Phaeophyta, Fucales) do litoral dos estados do Rio de Janeiro e São Paulo, Brasil. Revista Brasileira de Botânica, 23: 121-132.

THACKER, R.W.; GINSBURG, D.W. \& PAUL, V.J. 2001. Effects of herbivore exclusion and nutrient enrichment on coral reef macroalgae and cyanobacteria. Coral reefs, 19: 318-329.

VILLAÇA, R. \& PITOMBO, F.B. 1997. Benthic communities of shallow-water reefs of Abrolhos, Brazil. Revisata Brasileira de Oceanografia, 45: 35-43.

WYNNE, M.J. 2005. A checklist of benthic marine algae of the tropical and subtropical western Atlantic: second revision. Nova Hedwigia, 129: 1-154.

YONESHIGUE, Y. \& VILLAÇA, R.C. 1989. Antithamnion tenuissimum (Ceramiaceae, Rhodophyta) dans la région de Cabo Frio (État de Rio de Janeiro, Brésil). Première citation pour l'Atlantique Sud. Cryptogamie Algologie, 10: 325-335.

ZAR, J.H. 1996. Biostatistical analysis. Prentice-Hall, Londres.

Submetido em 12/01/2008. Aceito em 28/03/2008. 